\title{
Álvares de Azevedo: um poeta cismarento
}

José Américo Miranda

Universidade Federal de Minas Gerais

\begin{abstract}
CISMAR
Fala-me, anjo de luz! és glorioso À minha vista na janela à noite, Como divino alado mensageiro Ao ebrioso olhar dos frouxos olhos Do homem que se ajoelha para vê-lo Quando resvala em preguiçosas nuvens Ou navega no seio do ar da noite.
\end{abstract}

Romeu

Ai! quando de noite, sozinha à janela, Coa face na mão eu te vejo ao luar, Por que, suspirando, tu sonhas, donzela?

A noite vai bela,

E a vista desmaia

Ao longe na praia

Do mar!

Por quem essa lágrima orvalha-te os dedos, Como água da chuva a cheiroso jasmim? Na cisma que anjinho te conta segredos?

Que pálidos medos?

Suave morena,

Acaso tens pena

De mim? 
Donzela sombria, na brisa não sentes

A dor que um suspiro em meus lábios tremeu?

$E$ a noite, que inspira no seio dos entes

Os sonhos ardentes,

Não diz-te que a voz

Que fala-te a sós

Sou eu?

Acorda! não durmas da cisma no véu!

Amemos, vivamos, que amor é sonhar!

Um beijo donzela! Não ouves? no céu

A brisa gemeu...

As vagas murmuram...

As folhas sussurram:

Amar!

(Álvares de Azevedo, Poesias completas, p. 57)

abemos bem que o romantismo, na história da literatura moderna, foi o momento de deslocamento máximo, na direção do poeta, do foco de interesse do poema. Data desse momento histórico a consolidação da mudança da noção de arte mimética, associada à teoria da arte clássica, para arte expressiva, sinal dos novos tempos. Tal mudança ficou assim expressa na teoria do teatro publicada na Revista da Sociedade Filomática (n. 3, de [ago] 1833, n. 4, de set. 1833, n. 5, de out. 1833 e n.6, de dez. 1833) por Francisco Bernardino Ribeiro, Justiniano José da Rocha e Antônio Augusto de Queiroga, na passagem em que assinalam a distinção entre a tragédia clássica e a tragédia moderna:

Quem vê que os crimes são obra do destino, pode temê-lo, mas não se acautela porque o que foi uma vez determinado, não se pode evitar; quem vê porém que o verdadeiro 
inimigo de sua ventura está dentro de si próprio, quem observa nos outros os males, que as paixões individuais produzem, não pode deixar de reprimir os seus movimentos desordenados. A tragédia antiga só excitava compaixão no meio dos maiores crimes, a moderna além desse sentimento gera na alma do espectador o receio de si mesmo. ${ }^{1}$

A epígrafe do poema de Álvares de Azevedo, tradução "algo livre", do próprio poeta, segundo Péricles Eugênio da Silva Ramos, ${ }^{2}$ é trecho da cena II, segundo ato, da tragédia Romeu e Julieta. Trata-se da cena noturna em que Romeu está no jardim dos Capuletos, rondando a morada de Julieta, e ela aparece à janela, onde se debruça, e apoia o rosto na mão. Tudo isso tem importância para a compreensão exata e clara do poema, conforme se verá. E tudo isso sabemos pela boca de Romeu, que fala para que, nos termos das convenções dramáticas, saiba o público o que lhe vai no pensamento.

No poema de Álvares de Azevedo, é a epígrafe que lança luz sobre esse aspecto, o poeta ronda a casa de sua amada, ela está diante dele, com a face na mão, e contempla o mar; e, como Romeu, ele se dirige a ela - mas apenas em pensamento. Na poesia lírica, território próprio da intimidade, não há necessidade da expressão exterior, em altas vozes, das ideias de quem se expressa, como no teatro se faz.

No trecho que serve de epígrafe aos versos, Romeu fala sozinho, em solilóquio, no êxtase amoroso. Julieta aparece à janela; também ela fala sozinha, e ainda não se deu conta da presença dele nojardim. Antes de Romeu pronunciar as palavras da epígrafe, ele diz algo que ressoa no corpo do poema:

Olhai como [ela] apoia o rosto na mão!

${ }^{1}$ RIBEIRO; ROCHA; QUEIROGA. In: QUEIROGA, 1999, p. 75.

${ }^{2}$ RAMOS, 2002, p. 57, Nota. 
Eles ainda não se comunicaram. Ela ainda não tem conhecimento da presença dele nas proximidades. As palavras da epígrafe desempenham um papel importante, pois desenham na imaginação do leitor a cena da enunciação, em que o poeta, a certa distância, contempla a amada em sua janela, sem que ela o veja. Embora endereçadas a ela, as palavras ditas no poema, como as de Romeu, são um solilóquio. A epígrafe é, pois, funcional: é a partir da relação entre ela e os versos que se pinta com clareza a cena noturna, a situação imaginária em que surgem as palavras do poeta.

\section{II}

O poema começa justamente com uma interjeição, "Ai!", palavra pertencente à categoria que as gramáticas nos descrevem como "uma espécie de grito com que traduzimos de modo vivo nossas emoções." ${ }^{3} \mathrm{E}$, observando o poema como um todo, constatamos imediatamente que as estrofes inicial e final terminam por pontos de exclamação, que servem justamente para expressar pontos de vista subjetivos; ao passo que as estrofes intermediárias terminam por pontos de interrogação, que pressupõem, como correlato do "eu", uma outra subjetividade, uma segunda pessoa, um "tu".

Não há, em todo o poema, um só ponto final: nada é, nada está em paz; tudo é revolto, tudo é tumulto. Por quê? Porque tudo é entendido como parte integrante do "eu" e vive os seus mesmos conflitos. Há também o uso das reticências, que, também, introduzem uma inflexão de natureza emocional nos versos em que aparecem.

${ }^{3}$ CUNHA, 1976, p. 547. 
Enfim, com base apenas na pontuação, poder-se-ia dizer que o poema é ultrarromântico. Mas é necessário examinar tudo mais de perto, atentar no sentido e na forma dos versos.

Cada uma das quatro estrofes do poema tem sete versos. Embora compostas com versos de três medidas distintas, sendo heterométricas portanto, as estrofes mantêm entre si um paralelismo estrutural rigoroso, que se organiza de acordo com o seguinte padrão: os três primeiros versos são hendecassílabos, ou de arte maior; os três versos seguintes (quarto, quinto e sexto) são pentassílabos ou redondilhos menores; e, por fim, o último é dissílabo. Dos três metros empregados, os menores são segmentos rítmicos dos de medida imediatamente superior o que os integra à medida deles, ou faz com que os de medida maior se estendam para além de si mesmos.

O primeiro verso rima com o terceiro e o quarto, e o segundo ecoa no último. Esse sistema, de algum modo, une a parte da estrofe em metros longos à parte em metros curtos. $\mathrm{Na}$ segunda parte da estrofe, o quinto verso rima com o sexto. $\mathrm{O}$ último, conforme já se observou, é uma espécie de eco do segundo. A regularidade fisionômica das estrofes se reveste de um particular interesse funcional, que a análise revelará.

No que diz respeito ao ritmo, todos os hendecassílabos seguem à risca o preceito de resultarem da soma de dois segmentos pentassilábicos, cada um com acentos na segunda e na quinta sílabas, o que dá o resultado final de acentuação na segunda, na quinta, na oitava e na décima primeira sílabas do verso de arte maior.

Esse verso, empregado com frequência pelos poetas românticos, era concebido como resultado da justaposição de dois pentassílabos, que formavam os hemistíquios do verso de arte maior. É esse o esquema do primeiro verso do poema:

$$
\text { Ai!/ quan/do/ de/ noi/te, // so/zi/nha à/ ja/ne/la, }
$$


Ambos os hemistíquios, nesse caso, são graves e apresentam acentos nas segunda e quinta sílabas. Quando o primeiro hemistíquio é grave, a contagem silábica atual, à francesa, obtém um total de onze sílabas onde o sistema antigo, cujas regras se notam ainda em versos da geração romântica que se seguiu à de Álvares de Azevedo, como em Fagundes Varela e em Castro Alves, obtinha doze (porque levava em conta o fato de ser a nossa uma língua de ritmo grave, o que exigia a contagem da última sílaba átona do verso).

A mesma regularidade não acontece com o segundo verso, que obtém o mesmo ritmo com recursos inteiramente diversos.

Coa/fa/ce/ na/ mão / / eu/ te/ ve/jo ao/lu/ar,

Nesse caso, ambos os hemistíquios são agudos. Isolados, o primeiro tem cinco sílabas, enquanto o segundo pode ter cinco ou seis, dependendo de uma sinérese em "lu-ar", que, em havendo a sinérese, passa a ter valor de apenas uma sílaba, por ditongação do hiato. $\mathrm{O}$ primeiro hemistíquio tem acentos nas segunda e quinta sílabas; o segundo, na terceira e na quinta. Com a justaposição dos dois versos para a composição do de arte maior, do ponto de vista rítmico, a primeira sílaba do segundo hemistíquio entra no lugar da átona final ausente do primeiro hemistíquio, e o que resta do segundo hemistíquio dá justamente um pentassílabo com acentos nas segunda e quinta sílabas. Evidentemente, como o segundo hemistíquio é também agudo, para que tenha as doze sílabas do verso de arte maior (pela medida antiga), há de se contar mais uma, além da tônica final. A pausa de final de verso assume, então, musicalmente, o valor de uma sílaba. Repare-se que a composição desse hendecassílabo se deu por meio de recursos muito diferentes dos do primeiro verso do poema. Apesar disso, é notável a unidade do verso, que só como hendecassílabo assume, ao mesmo tempo, unidade rítmica e de sentido. 
No primeiro verso da segunda estrofe, obtém o poeta o hendecassílabo de ritmo idêntido por um terceiro modo:

Por/ quem/ es/sa/ lá/gri / /ma or/va/lha/-te os/ de/dos, Aqui há um primeiro hemistíquio esdrúxulo, com acentos na segunda e na quinta sílabas, no qual a contagem silábica anterior a Castilho dava como uma as duas sílabas átonas finais, pois se contava apenas uma além da tônica. O segundo hemistíquio é um pentassílabo grave, com acentos na segunda e na quinta sílabas. Como a sílaba final do primeiro hemistíquio é interior ao verso, na composição do hendecassílabo ela não poderia ser desprezada - especialmente nos termos do sistema castilhiano de medida dos versos; o caso se resolve pela sinalefa que une a sílaba final de "lá-gri-ma" à inicial de "or-va-lha", de modo que as duas sílabas se fundem numa só. O resultado é um hendecassílabo perfeito, com o mesmo andamento 2-5-8-11 dos outros. Como se vê, o poeta manipulava amplamente os recursos de que dispunha, para alcançar a regularidade rítmica.

Nos versos segundos da segunda e terceira estrofes, é outra a solução:

Co/moá/gua/ da/ chu/va a / / chei/ro/so/ jas/mim?

A/ dor/ que um/sus/pi/ro em // meus/lá/bios/tre/meu?

Em ambos, o primeiro hemistíquio é um pentassílabo grave, com acentos na segunda e na quinta sílabas. Os segundos hemistíquios são hexassílabos que perdem sua primeira sílaba para os primeiros (as preposições " $a$ ", no primeiro caso; e "em", no segundo), por sinalefa. Assim, as unidades rítmicas se descasam das unidades de sentido, e só na totalidade das onze (ou doze) sílabas o conjunto assume sua condição de verso: a soldadura dos dois hemistíquios resulta no hendecassílabo de andamento 2-5-8-11, como todos os outros. Em ambos os casos, também, o segundo hemistíquio é agudo, o que exigiria, para 
a composição das doze sílabas do verso de arte maior (segundo as regras do sistema antigo, anterior à reforma de Castilho), a contagem de mais uma sílaba (na verdade inexistente), que seria a átona final.

Por fim, um último esquema aparece nos três versos de arte maior da última estrofe:
A/cor/da!/ não/ dur/mas / / da/ cis/ma/ no/ véu! $\mathrm{A} / \mathrm{me} / \mathrm{mos} /$, vi/va/mos //, que a/mor/é/ so/nhar! $\mathrm{Um} / \mathrm{bei} / \mathrm{jo} / \mathrm{don} / \mathrm{ze} / \mathrm{la}$ ! / / Não/ ou/ves/? no/ céu

Em todos eles o primeiro hemistíquio é um pentassílabo grave, com acentos na segunda e na quinta sílabas, e o segundo um pentassílabo agudo, com o mesmo esquema de acentos. $\mathrm{O}$ antigo sistema de contagem exigiria a contagem de mais uma sílaba (inexistente na realidade), que seria a átona final do verso. Como se vê, os recursos de composição do verso de arte maior pelo poeta foram os mais variados.

A esse conjunto de três versos de arte maior que inicia todas as estrofes segue-se, em cada uma delas, outro conjunto de três pentassílabos, todos com acentos na segunda e quinta sílabas. E, por fim, cada estrofe termina por um sétimo verso dissílabo.

A disposição dos versos cria dois campos visuais principais em cada estrofe: o que é território dos versos de arte maior, e o que o é dos versos pentassílabos - cujo último, somado ao dissílabo final, resulta em inusitado octossílabo (um dos menos usados versos da língua portuguesa). Essa disposição gráfica, assim como a peculiaridade rítmica da parte final de cada estrofe, cria, em cada uma delas, uma espécie de topografia, que tem certa funcionalidade na expressão formal das ideias no poema. É o que se há de constatar. 


\section{III}

Os sete versos de cada estrofe, como já foi apontado, apresentam o seguinte esquema de rimas, que é fixo: ABAAccb. Isso equivale a dizer: por um lado, o verso dissílabo, que encerra cada estrofe, ecoa e recupera o segundo, que havia ficado solto; por outro, o primeiro verso de arte menor rima sempre com oúltimo de arte maior, o que os associa intimamente. Como se verá, a ligação entre esses dois versos associados pela rima, e a consequente ligação entre os territórios dos versos de arte maior e dos pentassílabos subsequentes, tem particular significação na estrutura das estrofes.

Quanto à rima que associa o segundo e o último versos de cada estrofe, ela tem como consequência a formação, no plano semântico, de pares de vocábulos indicativos de algo muito valioso e pertinente para a compreensão do poema como um todo: o par "luar/mar", na primeira estrofe, evoca o cosmos, o universo em sua infinitude; o par "jasmim $/ \mathrm{mim}$ ", em que a segunda palavra se encontra inteiramente contida na primeira, aponta para a fragilidade do "eu" que fala no poema; o par "tremeu/eu", responde parcialmente à expectativa gerada pela rima anterior, uma vez que o "eu" encontra-se aprisionado em "tremeu" e, com isso, toma-lhe a significação, como se a realizasse em seu corpo; e no par "sonhar/amar" remetem ambos os vocábulos à interioridade desse "eu" que, ao que tudo indica, abarca em si o dentro e o fora, um estado de alma e uma paisagem.

\section{IV}

A composição das estrofes, que as organiza num conjunto de versos de arte maior e outro de arte menor, resulta, em cada uma delas, na delimitação de dois campos: o primeiro, constituído pelos três primeiros versos; o segundo, pelos quatro seguintes. 
Na primeira estrofe, são estes os versos do primeiro campo:

Ai! quando de noite, sozinha à janela,

Coa face na mão eu te vejo ao luar,

Por que, suspirando, tu sonhas, donzela?

Neles, o poeta não se furta à exposição de si mesmo naquilo que diz: o "eu" que fala logo se deixa ver. A exclamação inicial do primeiro verso, seguida por letra minúscula, parece transmitir caráter exclamativo a todo o período, que, pode-se dizer, perde assim o contorno que o limita em seu princípio. $\mathrm{O}$ segundo verso contém um segmento que se poderia dizer ambíguo, já que se pode referir tanto à donzela que se encontra à janela quanto ao poeta que a vê: trata-se da expressão "coa face na mão" -; é razoavelmente claro que a expressão se refere à moça, mas não há rigorosamente nada que impeça o entendimento de que o atributo poderia muito bem servir ao poeta. A idéia de que a expressão se refere à moça na janela é dada pela epígrafe do poema, pois Julieta, à janela, também tinha o rosto apoiado na mão. Num poema de outro poeta contemporâneo de Álvares de Azevedo, "Minha Mãe", de Casimiro de Abreu, podem ser encontradas essas mesmas palavras, referindo-se elas, no caso, ao próprio poeta:

Nas horas caladas das noites d'estio

Sentado sozinho co'a face na mão,

Eu choro e soluço por quem me chamava

- "Oh filho querido do meu coração!" -

- Minha Mãe! -4

Se essa passagem do poema de Álvares de Azevedo é ambígua, se se aplica tanto ao amante quanto à amada, ela anuncia, na própria matéria do verso, a fusão dos seres, a participação de

${ }^{4}$ ABREU, 1955, p. 78. (“Minha Mãe") 
um no outro, que resultará numa só totalidade. Torna-se manifesto, aí, o desejo de realização amorosa de que o poema tenta ser a representação, ou, mais propriamente, por se tratar de um poema, a apresentação. É preciso investigar a forma, para verificar se o poema realiza nela aquilo de que fala, se ele nos põe diante dos olhos e dos ouvidos o seu objeto; isto é, se ele encontra, para a ideia, um correlativo objetivo. Ao final do terceiro verso, o ponto de interrogação, em posição simétrica à do "eu" inicial indiciado pela exclamação "Ai!", aponta para a segunda pessoa gramatical, para o destinatário daquele pensamento - a moça na janela.

\section{V}

$\mathrm{O}$ que faz a donzela à janela? Sonha e suspira. Cisma. $\mathrm{O}$ título do poema é "Cismar", e, nele, o verbo vem no infinitivo, sem a designação do sujeito. $\mathrm{Na}$ acepção de "ficar absorto em pensamentos", o verbo é intransitivo. Portanto, se falta algo ao título do poema, para que ele adquira clareza total, essa falta é a do sujeito. Verificar-se-á, mais adiante, se isso faz sentido.

Resumindo: o terceto inicial em versos hendecassílabos começa por uma exclamação, por um extravasamento do "eu"; porém, ele se organiza de tal modo que termina por uma interrogação, realizando uma espécie de ponte, do "eu" ao "tu", do poeta à donzela. Ela se encontra lá, à distância, na janela, e ele cá, olhando-a, mas, de qualquer modo, e de algum modo, já ligados, pela estrutura do período e pela interseção de suas subjetividades, no interior da frase, representada por aquela parte ambígua do segundo verso. Assim, se as subjetividades de ambos são campos distintos, há um território partilhado, ainda que parcialmente, por ambos: na sintaxe da frase, justamente na parte situada no segundo verso, a meio caminho entre o "Ai!" inicial e o ponto de interrogação final, a 
expressão "coa face na mão", que tanto se pode aplicar ao poeta como à donzela.

Os quatro versos seguintes, três pentassílabos e um dissílabo, compõem uma moldura paisagística para o quadro em que a moça é vista:

\section{A noite vai bela, E a vista desmaia Ao longe na praia Do mar!}

Nessa parte, todo o campo dos versos é feito de elementos plásticos do mundo exterior. A rima associa o "luar", elemento distante da paisagem, ao "mar", elemento paisagístico que, embora próximo, é imensurável. Paira na estrofe a ameaça de uma indefinição de limites.

Como na primeira parte da estrofe, há em sua segunda metade, um conjunto de significados que tanto poderia estar relacionado com a donzela, como poderia estar relacionado ao "eu" que fala no poema. Trata-se do trecho "E a vista desmaia / Ao longe na praia". Se escolhemos ler o poema segundo os padrões referenciais da arte clássica, em que a linguagem se volta predominantemente para o objeto, a vista que desmaia é a da donzela; mas se optarmos por uma leitura nova, a frase admite outra compreensão, que não precisa necessariamente desprezar a leitura anterior, mas que a incorpora à outra: esses dois versos tornam-se novamente indícios formais de um campo comum a amante e amada. Eles se fundem por meio dos versos, que se referem simultaneamente a ambos. Não se deve propor o entendimento de que a parte assinalada se refira exclusivamente ao poeta: isso seria uma interpretação redutora, cega para o que a mensagem tem de mais certo - o fato de que o poeta se refere ao olhar da amada.

Nessa primeira estrofe, o território dos versos hendecassílabos é, pois, ocupado por uma indagação, que é feita pelo 
poeta à amada, ao passo que o campo dos versos redondilhos menores e do verso final dissílabo constitui o território de uma exclamação; diríamos, então, que nele se expressa o poeta. Nos primeiros versos também o poeta se expressa, mas a indagação é dirigida, implica a presença da mulher. Nos versos finais o poeta parece se apresentar em território mais estritamente seu.

\section{VI}

Na estrofe seguinte, também o espaço reservado à natureza e à exclamação do poeta na estrofe anterior é invadido pelas indagações dirigidas à amada. A fronteira entre um campo e outro se desfaz, tudo é um território único, em que estão presentes amante e amada. Esse fato, de natureza formal, no poema "Cismar", põe em perspectiva, no horizonte da leitura, a expressão camoniana: "Transforma-se o amador na coisa amada." Entretanto, embora ambos os espaços sejam tomados pelo mesmo tipo de interrogações (sempre dirigidas à mesma pessoa), deve-se reconhecer que as interrogações do primeiro espaço são umas, e as do segundo, outras. Um dado adicional aparece, ainda, no verso dissílabo final: um pronome de primeira pessoa, "mim", justapõe-se agora ao ponto de interrogação - índice da presença da moça a quem o poeta se dirige.

O fenômeno da invasão do que chamamos "território do poeta", ou seja, o dos versos pentassílabos, em que ele se expressa exclamativamente, pela instância da subjetividade da amada, avança ainda mais na estrofe seguinte. $\mathrm{O}$ desmancharse das fronteiras entre os dois campos torna-se mais intenso e notável. Além de ambos os espaços estarem preenchidos por interrogações, há uma que começa no primeiro território (o dos versos hendecassílabos) e termina no segundo (o dos pentassílabos): 
E a noite, que inspira no seio dos entes

Os sonhos ardentes,

Não diz-te que a voz

Que fala-te a sós

Sou eu?

O pronome que se justapõe ao ponto de interrogação, no verso dissílabo final da estrofe, é agora o "eu" - "em pessoa".

\section{VII}

Na última estrofe o fenômeno alcança seu resultado final: a fusão amorosa parece completar-se, e, conforme se verá, há ainda mais do que isso. A primeira parte da estrofe, até o primeiro hemistíquio do terceiro verso, é constituída por exclamações, expressões do sentimento do poeta e, ao mesmo tempo, apelos veementes à amada (que têm um efeito semelhante ao das interrogações):

Acorda! não durmas da cisma no véu!

Amemos, vivamos, que amor é sonhar!

Um beijo, donzela!

A partir do segundo hemistíquio desse verso retorna uma indagação, seguida por expressivos versos terminados por reticências e com um supreendente final. Entre o campo dos versos hendecassílabos e o dos pentassílabos persiste a continuidade sintática já manifestada na estrofe anterior:

Não ouves? no céu

A brisa gemeu...

Por fim, na última estrofe acontece ainda algo importante. No final do último verso hendecassílabo retornam os elementos da natureza. Retomemos os versos da primeira estrofe, em que eles primeiro se apresentaram 
A noite vai bela,

E a vista desmaia

Ao longe na praia

Do mar!

para compará-los aos da última:

A brisa gemeu....

As vagas murmuram...

As folhas sussuram:

Amar!

Em ambos os casos, são as únicas ocorrências, em todo o poema, de elementos exteriores ao poeta e sua amada. A conversão do amante em amada, a fusão amorosa, manifestada na forma do poema pela corrosão dos limites que os separavam na primeira estrofe, avança ainda mais na última estrofe, quando a natureza é retomada. Toda ela participa do processo amoroso: a brisa "geme", as vagas "murmuram", as folhas "sussurram" - e sussurram o quê? Justamente a palavra "amar", culminação do percurso realizado, que recupera, pela rima, o próprio título do poema - fechando o círculo da forma. O verbo vem no infinitivo: realização platônica, erotismo vivido como experiência pura da vida interior. Vida que tudo envolve e de tudo, a natureza inclusive, participa.

Também o título do poema é um verbo no infinitivo "Cismar" -, a que falta o sujeito. Um poeta cismarento, uma amada cismarenta, e, por que não, uma natureza cismarenta. Tudo cisma. Tudo se absorve em outro infinitivo, "Amar", atributo e destino universal de todos os seres, de toda a natureza. 


\section{Referências}

ABREU, Casimiro de. Obras de Casimiro de Abreu. Apuração e revisão do texto, escorço biográfico, notas e índices por Sousa da Silveira. Rio de Janeiro: Ministério da Educação e Cultura, 1955. p. 78.

ALI, M. Said. Versificação portuguesa. Rio de Janeiro: Instituto Nacional do Livro, 1948.

AZEVEDO, Álvares de. Poesias completas. Ed. Crítica de Péricles Eugênio da Silva Ramos. Campinas: Unicamp, 2002.

AZEVEDO FILHO, Leodegário Amarante de. A técnica do verso em português. Rio de Janeiro: Acadêmica, 1971.

CUNHA, Celso Ferreira. Gramática da língua portuguesa. Rio de Janeiro: FENAME, 1976.

QUEIROGA, Antônio Augusto de. Obras. Belo Horizonte: Orobó, 1999.

REVISTA da Sociedade Philomatica. São Paulo: Tipografia do Novo Farol Paulistano, 1977. [Edição fac-similar patrocinada pela Metal Leve S. A.]

\section{Resumo}

Este artigo analisa "Cismar", de Álvares de Azevedo, investigando as soluções formais encontradas pelo poeta para dar expressão ao conteúdo ideacional do poema.

\section{Abstract}

This article analyzes Álvares de Azevedo's poem entitled "Cismar", investigating the formal techniques employed by the poet to convey the work's main ideas. 